Davids, S.F. et al. (2012). Vulnerable diseases affecting child mortality in Sierra Leone: emerging health issue. Journal of Asian and African Studies, 48(3): 348-369

\title{
Vulnerable diseases affecting child mortality in Sierra Leone: emerging health issue
}

\author{
Saarah F Davids, Sathiya Appuni and Latief Abduraghiem
}

\begin{abstract}
Child mortality in Sierra Leone is the highest ranked in the world. The main causes for child mortality are maternal factors, environmental factors and health factors. Minimal research has been carried out on health factors in Sierra Leone. The objective of this study is to see how maternal and environmental factors have an effect on health factors, which in turn cause child mortality. The data used were from the 2008 Sierra Leone Demographic and Household Survey (SLDHS). The study showed that child mortality had statistically significant factors associated with it: place of residence, birth number, religion and type of toilet facility. Furthermore, the SLDHS had not given much information regarding the cause of diseases affecting children, so we looked only at the effects they had on children. Acute respiratory infections, diarrhoea and measles each had one variable that was statistically significant. As for pneumonia, there were no variables associated with children contracting the disease.
\end{abstract}

\section{Background}

Child mortality is a subject that has been looked at, but not really invested in by a number of governments worldwide. In 1970 it was estimated that the amount of children who had died under the age of five throughout the world was 17 million children a year (Gordon et al., 2004). This number had been reduced to about nine million children a year in 2009 worldwide (Morley, 2010). The reduction was good overall. However, the decline only affected certain countries, while others had done little or nothing to reduce their child mortality rates (Gordon et al., 2004). In 2010, the United Nations (UN) estimated that 16 third-world countries had managed to reduce their child mortality rate by $40 \%$ in the last two decades (United Nations [UN], 2010). This reduction, according to the Millennium Development Goals (MDG), is short of the target which the UN was aiming for (Steadland and Skoglund, 2008).

Furthermore, it has been estimated that one in five of the world's children reside in the sub- Saharan region (United Nations, 2010). Therefore researchers have made it a priority to tackle the child mortality rate in sub-Saharan Africa due to its increase between 1990 and 2008 of approximately 4 million to 4.4 million child deaths (United Nations, 2010). In addition, the World Health Organization (WHO) global indicators show that the nations with the lowest child mortality rates in 2000 were all 
first-world countries such as Iceland (3 deaths per 1,00o live births), Sweden (4 deaths per 1,000), Singapore (4 deaths per 1,000), Japan (5 deaths per 1,000) and Norway (5 deaths per 1,000; World Health Orginization, 2010). As for the five countries with the highest child mortality rates in 2000, namely Chad (205 deaths per 1,00o live births), Mali (217 deaths per 1,000), Angola (238 deaths per 1,000), Sierra Leone (252 deaths per 1,000) and Afghanistan (257 deaths per 1,000; World Health Orginization, 2010), these are all considered to be developing countries. Some of the developed and developing countries were able to reduce their child mortality rate by a significant margin. An example of a developed and developing country which were able to reduce their child mortality rates are Singapore and Ethiopia. In Singapore the government was able to reduce its child mortality rate from 8 per 1,000 in 1990 to 2 per 1,000 in 2008. As for Ethiopia, the government was able to reduce its child mortality rate from 202 deaths per 1,000 to 101 deaths per 1,000 over a period of 20 years (Institute for Health Metrics and Evaluation, 2010).

The developing countries that are faced with high child mortality rates have two main concerns: first, they have all faced war in the past few decades which has left their infrastructure in disarray. Second, diseases such as pneumonia, diarrhoea, measles, anaemia, polio and tuberculosis are affecting the child mortality rate in these countries, despite being curable through vaccination if detected early and treated immediately.

\section{Rationale and Study Objectives}

Sierra Leone has the highest child mortality rate (278.1 per 1,000) in the world in 2009. The child mortality rate in Sierra Leone between 1990 and 2000 was decreasing at an annual rate of 1.8 per 1,00o. However, this has subsequently changed. Child mortality started to increase between 2000 and 2010 to an annual rate of 3.5 per 1,000 (Institute for Health Metrics and Evaluation, 2010). One reason for the child mortality rate being high is that diseases have become a major cause of death for children (Kandeh, 1986; Oloo, 2005; Uddin et al., 2009). In order to alleviate this problem in recent years, the UN has entered Sierra Leone and has been assisting with healthcare in areas that do not have adequate healthcare, as well as informing the people of diseases and what these diseases could do to them and their children if not treated correctly (International Centre for Transitional Justice, 2010). Therefore this research will be looking at vulnerable diseases affecting children and how their environment affects them will assist in determining how Sierra Leone could decrease its child mortality rate at a much quicker pace.

The challenges that are evident when looking at vulnerable diseases affecting child mortality in Sierra Leone are related to three main components: the mother's background (maternal factors), the child's environment (environmental factors), and the vulnerable diseases affecting children (health factors). In Sierra Leone vulnerable diseases, such as diarrhoea, pneumonia, measles and acute respiratory diseases (ARI) are diseases that could easily be contracted by children in their living environments, no matter what conditions they may live in. However, the mother's characteristics also play a role, with her background, demographics and socio- economic factors determining whether or not the child would survive. The population of Sierra Leone, which mainly consists of children, is affected by these vulnerable diseases, which in a 
number of cases result in child deaths. These cases could be avoided if adequate healthcare was made available to the people of Sierra Leone. These vulnerable diseases could be significant to the child mortality rate in Sierra Leone, as was the case in Cuba. In a study by Behm (1983), it was found that Cuba had reduced its child mortality rate between 1970 and 1978 from 38.8 to 22.3 per 1,00o. Behm had further stated that the reason for the decrease was due to some vulnerable diseases, such as diarrhoea and respiratory infections, being reduced by preventing and treating these diseases in children. Therefore our objective for this study is to investigate to what degree maternal and environmental factors affect child mortality in Sierra Leone due to vulnerable disease.

\section{Context}

Child mortality in the world is a great issue that concerns many governments and their populations. For this reason it has been used to determine the health status of a country (Nannan and Hall, 2010). This means that if a large proportion of children are dying due to health issues, it is less likely that there will be enough people to repopulate the country for the future. If this were the case, the health status of the country would become poor, which would lead to little or no growth in the country's population (Skolnik, 2008). In developed countries, child mortality has very low levels. This is shown by the rankings of child mortality by the UN (United Nations, Department of Economic and Social Affairs, Population Division, 2011). However, the five countries with the highest child mortality rates are all developing countries. The rea- son for this is that a first-world country's government would allocate three basic needs to its entire population: basic healthcare, food and shelter. If these basic necessities were to be given to all people in less developed countries, the rate of child mortality might not be so high (Skolnik, 2008).

Sierra Leone has fewer than six million inhabitants and with the highest child mortality rate, this does not look good for future growth in the country. There are a number of theories to explain why the child mortality rate is at this high level. First, Sierra Leone has recently emerged from a civil war. Due to the fighting, the government's infrastructure had crumbled, making it difficult for basic needs to be distributed to its people. Second, the government has been switching hands for many decades due to political fighting, making it hard for the government to become stable. Third, the level of poverty in Sierra Leone is at an all-time low, making this country one of the poorest countries in the world (Turay, 2010).

The last census that was held in Sierra Leone was in 2004. The demographic and household survey (DHS) 2008 for Sierra Leone was used in this study (Measure DHS, 2008). The reason for using this survey is to determine the effects of serious diseases on child mortality, as one in four Sierra Leonean children is dying from preventable diseases. Diseases in Sierra Leone are a major concern for children under the age of five. The diseases affecting the population can be categorized into six groups, namely: food disease, waterborne disease, vector borne disease, water contact disease, aerosolized dust disease and soil contact disease. For this case, we will be defining the following diseases that are affecting children under the age of five: tuberculosis, malaria, polio, measles, diarrhoea and pneumonia. 


\section{Data and Methods}

\section{Data}

We used the Sierra Leone Demographic and Household Survey (SLDHS) data, especially looking at the children dataset. The SLDHS was completed in 2008, making the data collected a recent and accurate measure of the country's population. The census would also have been a good source. However, this was completed in 2004. The survey was based on a cross-sectional design as it allows researchers to assess the prevalence of conditions in the population. However, since both the out- come and the variables are measured at a particular point in time, the study is not strong in showing cause-effect relationships. This means that, when it comes to diseases, it is hard to determine what the causes are, as well as their effects, due to this design not being over a period of time, but rather a single point in time. The dataset consisted of 5,631 children, of which 588 had died and 5,043 were alive.

\section{Variable Selection}

The data were categorized into four groups: demographics, environment, socioeconomic and health. Each group has a number of variables that could be associated with child mortality.

Demographic Variables. Child survival was the main variable called 'child is alive'. This variable is the survival of the child; that is, the child is either alive ('yes') or not ('no'). The mother's age variable was redefined from seven categories to three categories. First we have mothers 'under 20', which consists of mothers aged 15 to 19. Second, we have mothers aged between ' 20 to 34' and third, we have mothers between the ages of ' 35 to 49'. The variable birth number was rede- fined into four categories. The first category was children born in the order of ' 1 to 3 '. The second category was children with the birth order ' 4 to 6' and the third category was those in the order of ' 7 to 9'. The final category was those children in the birth order of ' 10 to 13'. The variable reli- gion had six categories ('Christianity', 'Islam', 'Baha'I', 'traditional', 'none' and 'other') and redefined into three categories ('Christianity', 'Islam' and 'other'). The category 'other' included the religions such as 'Baha'I', 'traditional', 'none' and 'other'.

Socio-Economic Variables. The variable 'mother's education' was left as defined in the survey. The categories for 'mother's education' were as follows: 'no education', 'primary', 'secondary' and 'tertiary'. The variable 'mother's occupation' was redefined from 11 into five categories. The first category was for mothers who were 'not working'. The second category was for those working in the 'modern' sector. This category included mothers who worked as a professional, technical, man- ager, clerical or in sales. The third category was 'farming'. Mothers working in this sector were either self-employed working in agriculture or were agricultural employees. The fourth category was mothers working in the 'traditional' sector. The 'traditional' sector was defined as mothers working in services or as a house domestic. The fifth category was labelled 'manual', which included mothers who were skilled or unskilled in manual labour.

Environmental Variables. The variable 'place of residence' had two categories ('rural' and 'urban'). The household environment forms part of a child surroundings. This is where the 
child lives, plays and is taken care of. Also this is the potential place where a child could contract any vulnerable diseases. The 'source of water' could determine a number of diseases depending on where the person collected the water from and how it was treated. This variable was grouped as follows: the first category was labelled as 'piped'. This included water being piped into the dwelling, piped to a yard or plot, public tap or standpipe. The second category is 'tube well'. This includes the tube well or borehole. The third category was named 'dug well', which included the following categories: protected well and unprotected well. The fourth category is labelled as 'surface' water. This included categories such as protected spring, unprotected spring and river/dam/lake/ponds/stream/ canal/irrigation channel. The fifth category was called a 'tanker', which includes the categories tanker truck and cart with small tank. The sixth category was named 'bottle' water and the final category named 'other'.

The 'type of toilet' facility is important. For example, an underground pit might leak into the ground water supply. This will contaminate the water and could easily make people sick. The type of toilet facility is grouped as follows: first we have the category 'flush'. This includes the categories flush to piped sewer system, flush to septic tank, flush to pit latrine, flush to somewhere else and flush but don't know where to. Second, we have the category 'pit latrine' which includes the following categories: pit latrine, ventilated improved pit, pit latrine with slab, pit latrine without slab and open pit. Third, we have the category 'no facility' which included the following categories: no facility/bush/field. The fourth category was 'composting' toilet and included the categories bucket toilet and hanging toilet/latrine. The fifth category was named 'stream/river', while the final category was labelled as 'other'. As for those who answered 'not de jure resident', those people were excluded since they were not part of the household or probably just visiting for the day.

We also wanted to look at the dwelling material used to build the household. There were three main aspects we looked at from the household, as well as the material used to build them with, which were the floors, walls and roof. For the 'main floor material' we have three main groups which are: 'natural' (earth/sand, dung and stone), 'rudimentary' (wood planks, palm/bamboo), 'finished' (parquet or polished wood, ceramic tiles, cement, carpet) and other. The walls were grouped in a similar way. This included: 'natural' (no walls, cane/palm/trunks, dirt, mud bricks), 'rudimentary' (bamboo with mud, stone with mud, uncovered adobe, plywood, cardboard, reused wood, clay blocks, corrugated iron sheets, tarpaulin), 'finished' (cement, stone with lime/cement, bricks, cement blocks, covered adobe, wood planks/shingles) and other. And finally the roof, which was coded as follows: 'natural' (no roof, thatch/palm leaf, sod), 'rudimentary' (rustic mat, palm/bamboo, wood planks, cardboard, tarpaulin) and 'finished' (metal, wood, ceramic tiles, cement, roofing shingles, asbestos).

Health Variables. As for health variables, the following variables were looked at due to them being either the disease itself, or a symptom of the disease looked at in the study. The first variable is 'had diarrhoea recently'. This had four possible answers which were either: 'no', 'yes in last 24 hours', 'yes in last 2 weeks' and 'don't know'. The answer 'don't know' was taken out of the sample. The next variable was 'still has diarrhoea'. This variable had three possible answers, which were: 'no', 'yes' and 'don't know'. The answer 'don't know' 
was taken out of the sample. The third variable was 'had fever in last two weeks'. This variable was redefined as having only two possible answers rather than the original three. The two answers that was kept was 'no' and 'yes', while 'don't know' was taken out as this was used as a symptom to determine whether a child had contracted a possible disease. The fourth variable was 'short, rapid breath'. This variable was left as is, except that the answer 'don't know' was taken out. As for the fifth variable labelled 'has fever or cough now', this had five possible answers which were: 'no', 'yes fever only', 'yes cough only', 'yes both fever and cough' and 'don't know'. The answer 'don't know' was removed. The sixth variable was 'problem in chest or blocked or runny nose'. This question was given five possible options for answering. The answers were: 'chest only', 'nose only', 'both chest and nose', 'other' and 'don't know'. The two answers 'other' and 'don't know' were removed from the sample.

\section{Statistical Analysis}

The data were either nominal or ordinal. Cross-tabulation tables were used to show the distribution of two or more variables in a table. Each cell in the table shows the number of respondents who gave a specific combination of responses in each single cell. The statistical analyses used were Chi-square test for association and Logistic regression. The Chi-square test for independence, also called Pearson's Chi-square test or the Chi-square test of association, was used to discover if there existed a relationship between two categorical variables. Logistic regression was used to predict the occurrence of a disease contracted by a child, the dependent variable, by factors associated with child mortality, the independent variables.

\section{Limitation}

The researcher used the demographic and household survey. Although the sample had been randomly selected, it only constituted a section of the total population. The children dataset used came from the recollection of the mother. This could be biased as only mothers who are in the sample areas would have responded and not those who had emigrated or died prior to the survey taking place. Also, it would have depended on how well the mothers could recall their child's medical history. According to Lopez et al. (2002), only one-third of the world's countries have adequate systems that capture the cause of death, which does not include Sierra Leone. Therefore knowing exactly what the cause of death was is very unlikely. Sierra Leone has started to recover from a civil war that ended in early 2002. The country is still in the process of rebuilding its infrastructure and getting its population's documents in order. The survey did not record the cause of child's death, making it hard to see exactly why these children had died. Data from the variables, age of mother, age of child and age of death are also sometimes miscommunicated. For example, if a child is 11 months old, some mothers would round the age to one year old. Another example that is very important is when a child dies. There are normally two classifications: a child dies before 12 months, or 12 months to five years. This could make the data skewed and the analysis could be incorrect. Malnutrition is also a limitation as it is does not form part of the survey. However, it is one of the leading causes of death. Due to this study looking at diseases that cause child mortality, a study limitation is using a survey and not looking at the diseases over a period of time. If a cohort study data was used, we could determine the cause of the disease and how to treat it. In the SLDHS of 2008, there were no questions asked concerning the 
disease, ARI. However, symptoms of ARI were collected and used in the analysis to determine the proportion of children with ARI. In addition, the survey did not provide any conclusions regarding the cause of death, making it hard to determine if children had died due to ARI. Therefore the sample used to determine ARI in children was only taken from children who were alive, to see how it affects children.

\section{Findings}

\section{Descriptive Analysis}

More female children (304 out of 588 ) died than male children (284 out of 588 ). The majority of children (394 out of 588) had died to mothers between the ages of 20 and 34. The mothers between the ages of 35 and 49 had the second highest percentage (150 out of 588) of child deaths (see Table 1). More children had died while residing in the rural areas (358 out of 588) compared to those in the urban areas (230 out of 588). As for age at death, the majority of children (323 out of 588 ) had died in their first three years of life. In 2008, the percentage of children living in households with Islam as their belief system was $76 \%(4,289$ out of 5,614$)$, while Christianity accounted for $23 \%(1,271$ out of 5,614 ) and other religions approximately $1 \%$ (54 out of 5,614; Table 1 ). The majority of child deaths (472 out of 587) were from Islam households.

The male sample shows that at least $0.74 \%$ had shown symptoms of ARI, while in the female sample only $0.48 \%$ had shown symptoms (see Table 2 and Figure 1). However, a test of association was carried out to determine if the sex of a child is a determinant of whether the child would con- tract ARI.

Pneumonia was one of the diseases looked at as a possible cause of death. However, due to there being no cause of death stated, we looked at the proportion of children affected by pneumonia instead. Furthermore, the question of children having contracted pneumonia was not asked outright in the survey. Therefore symptoms of pneumonia were looked at to determine the proportion of children showing signs of contracting the disease. The symptoms most associated with pneumonia are short, rapid breaths, having a fever and cough, as well as having a problem in the chest. We compared the symptoms that included all these attributes to factors associated with child mortality. The results show that pneumonia is higher among children living in the rural areas compared to the children living in the urban areas. Furthermore, we found that chi-square (1) $=1.020, p=$ 0.312. As for the children with a birth number between one and three, the data indicated that approximately $0.37 \%$ had shown signs of pneumonia, while those whose numbers were between seven and nine had about $0.67 \%$ of children showing symptoms of pneumonia (Table 3). The result shows that birth order has a statistically higher significance than other variables. Therefore other variables' relationships with the dependent variable are intentionally not mentioned here. 
Table I. Percentage distribution of child mortality in Sierra Leone, 2008.

\begin{tabular}{|c|c|c|c|c|c|}
\hline \multirow[t]{2}{*}{ Characteristics } & \multicolumn{2}{|c|}{ Child is alive } & \multirow[t]{2}{*}{ Number of cases } & \multirow[t]{2}{*}{ Chi square } & \multirow[t]{2}{*}{$p$-value } \\
\hline & No (\%) & Yes (\%) & & & \\
\hline \multicolumn{6}{|l|}{ Sex of child } \\
\hline Male & 284 & 2,552 & 2,836 & 1.120 & 0.290 \\
\hline Female & 304 & $2,49 \mid$ & 2,795 & & \\
\hline \multicolumn{6}{|l|}{ Mothers age } \\
\hline$<20$ years & 0.6 & 99.4 & 336 & 520.811 & 0.000 \\
\hline 20-34 years & 0.6 & 99.4 & 3,479 & & \\
\hline 35-49 years & 0.65 & 99.35 & 1,228 & & \\
\hline \multicolumn{6}{|l|}{ Place of residence } \\
\hline Rural & 60.9 & 358 & 3,353 & 7.359 & 0.007 \\
\hline Urban & 39.1 & 230 & 1,690 & & \\
\hline \multicolumn{6}{|l|}{ Birth number } \\
\hline $\mathrm{I}-3$ & 9.80 & 90.20 & 3,295 & & \\
\hline 4-6 & 10.48 & 89.52 & 1,755 & 17.052 & 0.001 \\
\hline $7-9$ & 12.65 & 87.35 & 514 & & \\
\hline $10-12$ & 23.88 & 76.12 & 67 & & \\
\hline \multicolumn{6}{|l|}{ Religion } \\
\hline Christian & 8.26 & 91.74 & $|, 27|$ & & \\
\hline Islam & 11.00 & 89.00 & 4,289 & 13.364 & 0.020 \\
\hline Other & 18.52 & 81.48 & 54 & & \\
\hline \multicolumn{6}{|l|}{ Source of water } \\
\hline Piped & 10.56 & 89.44 & 1,089 & & \\
\hline Tube well & 13.20 & 86.80 & 409 & & \\
\hline Dug well & 10.36 & 89.64 & 2,095 & 5.067 & 0.408 \\
\hline Surface & 9.70 & 90.30 & 1,969 & & \\
\hline Tanker & 5.26 & 94.74 & 19 & & \\
\hline Bottle & II.II & 88.89 & 9 & & \\
\hline Other & 0 & 0 & 0 & & \\
\hline \multicolumn{6}{|l|}{ Type of toilet } \\
\hline Flush & 12.62 & 87.38 & 214 & & \\
\hline Pit latrine & 10.46 & 89.54 & 3,652 & & \\
\hline No facility & 9.81 & 90.19 & 1,387 & 11.269 & 0.046 \\
\hline Composting & 8.06 & 91.94 & 273 & & \\
\hline River/stream & 24.32 & 75.68 & 37 & & \\
\hline Other & 7.41 & 92.59 & 27 & & \\
\hline \multicolumn{6}{|l|}{ Source of energy } \\
\hline Yes & 10.37 & 89.63 & 5,026 & 0.016 & 0.898 \\
\hline No & 10.19 & 89.81 & 569 & & \\
\hline \multicolumn{6}{|l|}{ Mother's occupation } \\
\hline Not working & 10.95 & 89.05 & $\mathrm{I}, 142$ & & \\
\hline Modern & 10.63 & 89.37 & 1,561 & & \\
\hline Farming & 9.88 & 90.12 & 2,724 & & \\
\hline Traditional & 8.54 & 91.46 & 82 & 7.633 & 0.178 \\
\hline Manual & 18.39 & 81.61 & 87 & & \\
\hline Other & 0.00 & 100.00 & 1 & & \\
\hline
\end{tabular}


Table I. (Continued)

\begin{tabular}{|c|c|c|c|c|c|}
\hline \multirow[t]{2}{*}{ Characteristics } & \multicolumn{2}{|c|}{ Child is alive } & \multirow[t]{2}{*}{ Number of cases } & \multirow[t]{2}{*}{ Chi square } & \multirow[t]{2}{*}{$p$-value } \\
\hline & No (\%) & Yes (\%) & & & \\
\hline \multicolumn{6}{|l|}{ Main floor materials } \\
\hline Natural & 10.11 & 89.89 & 3,669 & & \\
\hline Rudimentary & 25.00 & 75.00 & 8 & 2.443 & 0.295 \\
\hline Finished & 10.77 & 89.23 & 1912 & & \\
\hline \multicolumn{6}{|l|}{ Main walls materials } \\
\hline Natural & 11.34 & 88.66 & 1,517 & & \\
\hline Rudimentary & 11.90 & 88.10 & 462 & 0.145 & 0.930 \\
\hline Finished & 11.27 & 88.73 & 1499 & & \\
\hline \multicolumn{6}{|l|}{ Main roof materials } \\
\hline Natural & 11.01 & 88.99 & 1,399 & & \\
\hline Rudimentary & 10.34 & 89.66 & 348 & 1.806 & 0.405 \\
\hline Finished & 9.74 & 90.26 & 3,634 & & \\
\hline
\end{tabular}

Source: Demographic and Household survey, Sierra Leone (2008).

There were two variables we merged together: children who had diarrhoea two weeks prior to the survey and children who still had diarrhoea at the time of the survey. These two variables were compared to possible factors associated with child mortality to determine which of these factors were also associated with diarrhoea. Furthermore, the results indicate that mothers between the ages of 20 to 34 had the second highest percentage of children affected by diarrhoea (Table 4). As for older mothers between the ages of 35 and 49 , the results indicated that there were approximately $1.55 \%$ of children who had contracted diarrhoea. The result shows that the birth number of a child and the percentage of children showing signs of measles indicate that measles was highest amongst children with a birth number between four and six. Furthermore, the results showed that the second highest percentage of cases were amongst children with the birth number between one and three. As for the third highest, this was among children in the order of seven to nine. Furthermore, there were no cases of measles for children with the birth number between 10 and 12 (Table 5). 
Table 2. Percentage distribution of children affected by ARI in Sierra Leone 2008.

\begin{tabular}{|c|c|c|c|c|c|}
\hline Characteristics & Has ARI (\%) & No ARI (\%) & Number of cases & Chi square & p-value \\
\hline \multicolumn{6}{|l|}{ Mother age } \\
\hline Under 20 & 0.6 & 99.4 & 336 & & \\
\hline $20-34$ & 0.6 & 99.4 & 3,479 & 0.036 & 0.982 \\
\hline $35-49$ & 0.65 & 99.35 & 1,228 & & \\
\hline \multicolumn{6}{|l|}{ Place of residence } \\
\hline Rural & 0.75 & 99.25 & 3,353 & 2.806 & 0.094 \\
\hline Urban & 0.36 & 99.64 & 1,690 & & \\
\hline \multicolumn{6}{|l|}{ Birth number } \\
\hline $1-3$ & 0.44 & 99.56 & 2,972 & & \\
\hline $4-6$ & 0.83 & 99.17 & $|, 57|$ & 4.838 & 0.184 \\
\hline $7-9$ & I.II & 98.89 & 449 & & \\
\hline $10-12$ & 0 & 100 & 51 & & \\
\hline \multicolumn{6}{|l|}{ Sex of child } \\
\hline Male & 0.74 & 99.26 & 2,552 & 1.425 & 0.233 \\
\hline Female & 0.48 & 99.52 & 2,491 & & \\
\hline \multicolumn{6}{|l|}{ Religion } \\
\hline Christian & 0.69 & 99.31 & 1,166 & & \\
\hline Islam & 0.6 & 99.4 & 3,817 & 0.377 & 0.828 \\
\hline Other & 0 & 100 & 44 & & \\
\hline \multicolumn{6}{|l|}{ Source of water } \\
\hline Piped & 0.41 & 99.59 & 974 & & \\
\hline Tube well & 0.28 & 99.72 & 355 & & \\
\hline Dug well & 0.59 & 99.41 & 1,878 & 3.000 & 0.700 \\
\hline Surface & 0.84 & 99.16 & $\mathrm{I}, 778$ & & \\
\hline Tanker & 0 & 100 & 18 & & \\
\hline Bottle & 0 & 100 & 8 & & \\
\hline \multicolumn{6}{|l|}{ Type of toilet } \\
\hline Flush & 0 & 100 & 187 & & \\
\hline Pit latrine & 0.7 & 99.3 & 3,270 & 2.145 & 0.829 \\
\hline No facility & 0.56 & 99.44 & $|, 25|$ & & \\
\hline Composting & 0 & 100 & 251 & & \\
\hline River/stream & 0 & 100 & 25 & & \\
\hline \multicolumn{6}{|l|}{ Source of energy } \\
\hline Yes & 0.39 & 99.61 & 511 & 0.476 & 0.490 \\
\hline No & 0.64 & 99.36 & 4,505 & & \\
\hline \multicolumn{6}{|l|}{ Mother's education } \\
\hline No education & 0.75 & 99.25 & 3,709 & & \\
\hline Primary & 0.15 & 99.85 & 652 & 4.726 & 0.193 \\
\hline Secondary & 0.33 & 99.67 & 613 & & \\
\hline Higher & 0 & 100 & 69 & & \\
\hline \multicolumn{6}{|l|}{ Mother's occupation } \\
\hline Not working & 0.39 & 99.61 & 1,017 & & \\
\hline Modern & 0.43 & 99.57 & 1,395 & & \\
\hline Farming & 0.81 & 99.19 & 2,455 & 4.255 & 0.513 \\
\hline
\end{tabular}


Table 2. (Continued)

\begin{tabular}{lllccc}
\hline Characteristics & Has ARI $(\%)$ & No ARI $(\%)$ & Number of cases & Chi square & p-value \\
\hline Traditional & 1.33 & 98.167 & 75 & & \\
Manual & 0 & 100 & 71 & & \\
$\quad$ Other & 0 & 100 & 0 & & \\
Main floor materials & & & & & \\
$\quad$ Natural & 0.79 & 99.21 & 3,298 & 6.255 & 0.513 \\
$\quad$ Rudimentary & 0 & 100 & 6 & & \\
$\quad$ Finished & 0.29 & 99.71 & 1,706 & & \\
Main walls materials & & & & & \\
$\quad$ Natural & 1.04 & 98.96 & 1,345 & & \\
$\quad$ Rudimentary & 0.49 & 99.51 & 407 & & \\
$\quad$ Finished & 0.38 & 99.62 & 1,330 & & \\
Main roof materials & & & & & \\
$\quad$ Natural & 0.8 & 99.2 & 1,245 & & \\
$\quad$ Rudimentary & 1.6 & 98.4 & 312 & & \\
$\quad$ Finished & 0.43 & 99.57 & 3,280 & & \\
\hline
\end{tabular}

Source: Demographic and Household survey, Sierra Leone (2008).

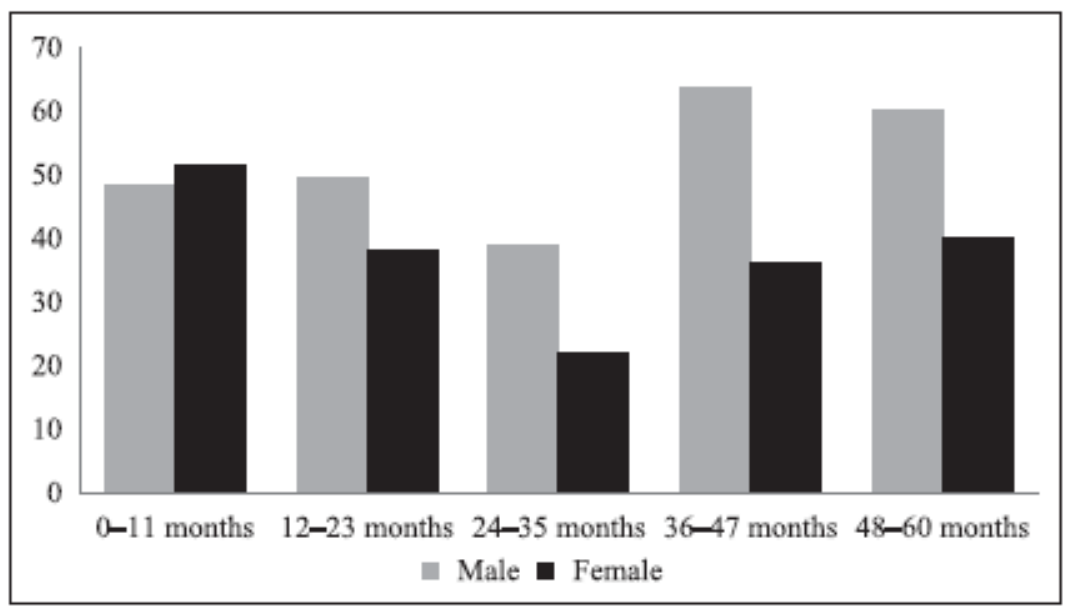

Figure I. Age at death in months by sex of child.

Source: Demographic and Household Survey, Sierra Leone (2008).

Table 3. Percentage distribution of children affected by Pneumonia in Sierra Leone 2008.

\begin{tabular}{llcccc}
\hline Characteristics & Has pneumonia (\%) & No S (\%) & Number of cases & Chi square & p-value \\
\hline Mother's age & & & & & \\
$\quad$ Under 20 & 0.00 & 100 & 336 & & \\
20-34 & 0.60 & 99.40 & 3,479 & 3.214 & 0.200 \\
$\quad 35-49$ & 0.33 & 99.67 & 1,228 & & \\
Place of residence & & & & & \\
$\quad$ Rural & 0.57 & 99.43 & 3,353 & 1.020 & 0.312 \\
$\quad$ Urban & 0.36 & 99.64 & 1,690 & & \\
\hline
\end{tabular}


Table 3. (Continued)

\begin{tabular}{|c|c|c|c|c|c|}
\hline Characteristics & Has pneumonia (\%) & No S (\%) & Number of cases & Chi square & p-value \\
\hline \multicolumn{6}{|l|}{ Birth number } \\
\hline $1-3$ & 0.37 & 99.63 & 2,972 & & \\
\hline $4-6$ & 0.70 & 99.30 & $1,57 \mid$ & 2.807 & 0.422 \\
\hline $7-9$ & 0.67 & 99.33 & 449 & & \\
\hline $10-12$ & 0.00 & 100.0 & 51 & & \\
\hline \multicolumn{6}{|l|}{ Sex of child } \\
\hline Male & 0.63 & 99.37 & 2,552 & 1.804 & 0.179 \\
\hline Female & 0.36 & 99.64 & 2,491 & & \\
\hline \multicolumn{6}{|l|}{ Religion } \\
\hline Christian & 0.69 & 99.31 & 1,166 & & \\
\hline Islam & 0.45 & 99.55 & 3,817 & 1.268 & 0.531 \\
\hline Other & 0.00 & 100.0 & 44 & & \\
\hline \multicolumn{6}{|l|}{ Source of water } \\
\hline Piped & 0.31 & 99.69 & 974 & & \\
\hline Tube well & 0.28 & 99.72 & 355 & & \\
\hline Dug well & 0.43 & 99.57 & 1,878 & 3.316 & 0.651 \\
\hline Surface & 0.73 & 99.27 & 1,778 & & \\
\hline Tanker & 0.00 & 100.0 & 18 & & \\
\hline Bottle & 0.00 & 100.0 & 8 & & \\
\hline \multicolumn{6}{|l|}{ Type of toilet } \\
\hline Flush & 0.00 & 100.0 & 187 & & \\
\hline Pit latrine & 0.49 & 99.51 & 3,270 & & \\
\hline No facility & 0.40 & 99.60 & 1,251 & 7.519 & 0.185 \\
\hline Composting & 0.02 & 99.98 & 251 & & \\
\hline River/stream & 0.00 & 100.0 & 25 & & \\
\hline \multicolumn{6}{|l|}{ Source of energy } \\
\hline Yes & 0.39 & 99.61 & 511 & 0.131 & 0.717 \\
\hline No & 0.51 & 99.49 & 4,505 & & \\
\hline \multicolumn{6}{|l|}{ Mother's education } \\
\hline No education & 0.49 & 99.51 & 3,709 & & \\
\hline Primary & 0.77 & 99.23 & 652 & $1.66 \mathrm{I}$ & 0.641 \\
\hline Secondary & 0.33 & 99.67 & 613 & & \\
\hline Higher & 0.00 & 100.0 & 69 & & \\
\hline \multicolumn{6}{|l|}{ Mother's occupation } \\
\hline Not working & 0.29 & 99.71 & 1,017 & & \\
\hline Modern & 0.36 & 99.64 & 1,395 & & \\
\hline Farming & 0.65 & 99.35 & 2,455 & 3.977 & 0.553 \\
\hline Traditional & 1.33 & 98.67 & 75 & & \\
\hline Manual & 0.00 & 100.0 & 71 & & \\
\hline Other & 0.00 & 100.0 & I & & \\
\hline \multicolumn{6}{|l|}{ Main floor materials } \\
\hline Natural & 0.61 & 99.39 & 3,298 & & \\
\hline Rudimentary & 0.00 & 100.0 & 6 & 2.254 & 0.324 \\
\hline Finished & 0.29 & 99.71 & 1,706 & & \\
\hline \multicolumn{6}{|l|}{ Main walls materials } \\
\hline Natural & 0.82 & 99.18 & 1,345 & & \\
\hline
\end{tabular}

(Continued) 
Table 3. (Continued)

\begin{tabular}{clcccc}
\hline Characteristics & Has pneumonia (\%) & No S $(\%)$ & Number of cases & Chi square & p-value \\
\hline Rudimentary & 0.25 & 99.75 & 407 & 3.180 & 0.204 \\
$\quad$ Finished & 0.38 & 99.62 & 1,330 & & \\
Main roof materials & & & & & \\
$\quad$ Natural & 0.56 & 99.44 & 1,245 & 1.743 & 0.418 \\
$\quad$ Rudimentary & 0.00 & 100.0 & 312 & & \\
$\quad$ Finished & 0.46 & 99.54 & 3,280 & & \\
\hline
\end{tabular}

Source: Demographic and Household survey, Sierra Leone (2008).

Table 4. Percentage distribution of children affected by diarrhoea in Sierra Leone 2008.

\begin{tabular}{|c|c|c|c|c|c|}
\hline Characteristics & Has diarrhoea (\%) & No diarrhoea (\%) & No of cases & Chi square & $p$-value \\
\hline \multicolumn{6}{|l|}{ Mother's age } \\
\hline Under 20 & 2.98 & 97.02 & 336 & & \\
\hline $20-34$ & 2.21 & 97.79 & 3,479 & 3.294 & 0.193 \\
\hline $35-49$ & 1.55 & 98.45 & 1,228 & & \\
\hline \multicolumn{6}{|l|}{ Place of residence } \\
\hline Rural & 2.03 & 97.97 & 3,353 & 0.265 & 0.606 \\
\hline Urban & 2.25 & 97.75 & 1,690 & & \\
\hline \multicolumn{6}{|l|}{ Birth number } \\
\hline $1-3$ & 2.19 & 97.81 & 2,972 & & \\
\hline $4-6$ & 1.91 & 98.09 & I,57| & 0.426 & 0.935 \\
\hline $7-9$ & 2.23 & 97.77 & 449 & & \\
\hline $10-12$ & 1.96 & 98.04 & 51 & & \\
\hline \multicolumn{6}{|l|}{ Sex of child } \\
\hline Male & 2.27 & 97.73 & 2,552 & 0.732 & 0.392 \\
\hline Female & 1.93 & 98.07 & 2,491 & & \\
\hline \multicolumn{6}{|l|}{ Religion } \\
\hline Christian & 2.40 & 97.60 & I,I66 & 0.644 & 0.725 \\
\hline Islam & 2.02 & 97.98 & 3,817 & & \\
\hline Other & 2.27 & 97.73 & 44 & & \\
\hline \multicolumn{6}{|l|}{ Source of water } \\
\hline Piped & 2.46 & 97.54 & 974 & & \\
\hline Tube well & 4.23 & 95.77 & 355 & & \\
\hline Dug well & 1.49 & 98.51 & $\mathrm{I}, 878$ & 12.355 & 0.030 \\
\hline Surface & 2.19 & 97.81 & 1,778 & & \\
\hline Tanker & 0.00 & 100.00 & 18 & & \\
\hline Bottle & 0.00 & 100.00 & 8 & & \\
\hline \multicolumn{6}{|l|}{ Type of toilet } \\
\hline Flush & 1.60 & 98.40 & 187 & & \\
\hline Pit latrine & 2.23 & 97.77 & 3,270 & & \\
\hline No facility & 1.76 & 98.24 & $|, 25|$ & 3.760 & 0.584 \\
\hline Composting & 0.03 & 99.97 & 251 & & \\
\hline
\end{tabular}


Table 4. (Continued)

\begin{tabular}{|c|c|c|c|c|c|}
\hline Characteristics & Has diarrhoea (\%) & No diarrhoea (\%) & No of cases & Chi square & p-value \\
\hline River/stream & 0.00 & 100.0 & 25 & & \\
\hline \multicolumn{6}{|l|}{ Source of energy } \\
\hline Yes & 1.96 & 98.04 & 511 & 0.067 & 0.795 \\
\hline No & 2.13 & 97.87 & 4,505 & & \\
\hline \multicolumn{6}{|l|}{ Mother's education } \\
\hline No education & 2.05 & 97.95 & 3,709 & & \\
\hline Primary & 2.45 & 97.55 & 652 & & \\
\hline Secondary & 1.96 & 98.04 & 613 & 0.718 & 0.869 \\
\hline Higher & 2.90 & 97.10 & 69 & & \\
\hline \multicolumn{6}{|l|}{ Mother's occupation } \\
\hline Not working & 1.77 & 98.23 & 1,017 & & \\
\hline Modern & 2.15 & 97.85 & 1,395 & 4.587 & 0.468 \\
\hline Farming & 2.08 & 97.92 & 2,455 & & \\
\hline Traditional & 5.33 & 94.67 & 75 & & \\
\hline Manual & 2.82 & 97.18 & 72 & & \\
\hline \multicolumn{6}{|l|}{ Main floor materials } \\
\hline Natural & 2.27 & 97.73 & 3,298 & & \\
\hline Rudimentary & 0.00 & 100.0 & 6 & 1.951 & 0.377 \\
\hline Finished & 1.70 & 98.30 & 1,706 & & \\
\hline \multicolumn{6}{|l|}{ Main walls materials } \\
\hline Natural & 2.08 & 97.92 & 1,345 & 0.023 & 0.988 \\
\hline Rudimentary & 1.97 & 98.03 & 407 & & \\
\hline Finished & 2.03 & 97.97 & 1,330 & & \\
\hline \multicolumn{6}{|l|}{ Main roof materials } \\
\hline Natural & 1.93 & 98.07 & 1,245 & & \\
\hline Rudimentary & 1.60 & 98.40 & 312 & 0.700 & 0.705 \\
\hline Finished & 2.20 & 97.80 & 3,280 & & \\
\hline
\end{tabular}


Table 5. Percentage distribution of children affected by measles in Sierra Leone (2008).

\begin{tabular}{|c|c|c|c|c|c|}
\hline Characteristics & Has measles (\%) & No measles (\%) & Number of cases & Chi square & p-value \\
\hline \multicolumn{6}{|l|}{ Mother's age } \\
\hline Under 20 & 0.89 & 99.11 & 336 & & \\
\hline $20-34$ & 0.03 & 99.97 & 3,479 & 2.909 & 0.233 \\
\hline $35-49$ & 0.33 & 99.67 & 1,228 & & \\
\hline \multicolumn{6}{|l|}{ Place of residence } \\
\hline Rural & 0.51 & 99.49 & 3,353 & 6.336 & 0.012 \\
\hline Urban & 0.89 & 99.11 & 1,690 & & \\
\hline \multicolumn{6}{|l|}{ Birth number } \\
\hline $1-3$ & 0.30 & 99.70 & 2,972 & & \\
\hline $4-6$ & 0.51 & 99.49 & $|, 57|$ & 1.679 & 0.642 \\
\hline $7-9$ & 0.22 & 99.78 & 449 & & \\
\hline $10-12$ & 0.00 & 100.0 & 51 & & \\
\hline \multicolumn{6}{|l|}{ Sex of child } \\
\hline Male & 0.47 & 99.53 & 2,552 & 1.864 & 0.172 \\
\hline Female & 0.24 & 99.76 & 2,491 & & \\
\hline \multicolumn{6}{|l|}{ Religion } \\
\hline Christian & 0.09 & 99.91 & 1,166 & & \\
\hline Islam & 0.45 & 99.55 & 3,817 & 3.397 & 0.183 \\
\hline Other & 0.00 & 100.0 & 44 & & \\
\hline \multicolumn{6}{|l|}{ Source of water } \\
\hline Piped & 0.10 & 99.90 & 974 & & \\
\hline Tube well & 0.28 & 99.72 & 355 & & \\
\hline Dug well & 0.37 & 99.63 & 1,878 & 3.027 & 0.696 \\
\hline Surface & 0.51 & 99.49 & 1,778 & & \\
\hline Tanker & 0.00 & 100.00 & 18 & & \\
\hline Bottle & 0.00 & 100.00 & 8 & & \\
\hline \multicolumn{6}{|l|}{ Type of toilet } \\
\hline Flush & 0.00 & 100.0 & 187 & & \\
\hline Pit latrine & 0.37 & 99.63 & 3,270 & & \\
\hline No facility & 0.48 & 99.52 & $1,25 \mid$ & 2.283 & 0.809 \\
\hline Composting & 0.00 & 100.0 & 251 & & \\
\hline River/stream & 0.00 & 100.0 & 25 & & \\
\hline \multicolumn{6}{|l|}{ Source of energy } \\
\hline Yes & 0.00 & 100.0 & 511 & 2.049 & 0.152 \\
\hline No & 0.40 & 99.60 & 4,505 & & \\
\hline \multicolumn{6}{|l|}{ Mother's education } \\
\hline No education & 0.38 & 99.62 & 3,709 & & \\
\hline Primary & 0.31 & 99.69 & 652 & 3.052 & 0.384 \\
\hline Secondary & 0.16 & 99.84 & 613 & & \\
\hline Higher & 1.45 & 98.55 & 69 & & \\
\hline \multicolumn{6}{|l|}{ Mother's occupation } \\
\hline Not working & 0.10 & 99.90 & 1,017 & & \\
\hline Modern & 0.36 & 99.64 & 1,395 & & \\
\hline Farming & 0.04 & 99.96 & 2,455 & 3.618 & 0.606 \\
\hline Traditional & 0.00 & 100.0 & 75 & & \\
\hline
\end{tabular}


Table 5. (Continued)

\begin{tabular}{llcccc}
\hline Characteristics & Has measles (\%) & No measles (\%) & Number of cases & Chi square & p-value \\
\hline $\begin{array}{l}\text { Manual } \\
\text { Main floor materials }\end{array}$ & 0.00 & 100.0 & 72 & & \\
$\quad$ & 0.36 & 99.64 & 3,298 & & \\
$\quad$ Natural & 0.00 & 100.00 & 6 & 0.026 & 0.987 \\
$\quad$ Rudimentary & 0.35 & 99.65 & 1,706 & & \\
$\quad$ Finished & 0.35 & & & & \\
Main walls materials & & 99.26 & 1,345 & 3.269 & 0.195 \\
$\quad$ Natural & 0.74 & 99.75 & 407 & & \\
$\quad$ Rudimentary & 0.25 & 99.70 & 1,330 & & \\
$\quad$ Finished & 0.30 & & & & \\
Main roof materials & & 99.52 & 1,245 & & \\
$\quad$ Natural & 0.48 & 99.04 & 312 & & \\
$\quad$ Rudimentary & 0.96 & 99.73 & 3,280 & & \\
$\quad$ Finished & 0.27 & & &
\end{tabular}

Logistic Regression

Logistic regression was used for the selected background variables chosen from the children data- set. There were three dependent variables: children having a cough for the last 24 hours, children having problems in the chest and children having diarrhoea. Several diseases influenced child mortality in the study area. Interestingly, our major concern reflects data consistency and the qual- ity of the data. These three dependent variables play a major role with the independent variables. These variables were used to evaluate the significance between each of the independent variables on the dependent variables. The dependent variables were dichotomous: if 'yes', coded as ' 1 '; if 'no', coded as 'o'; in other words, one of two outcomes: that is, either they had not contracted the disease $(0=$ no $)$ or they had contracted the disease $(1=$ yes $)$.

As for the independent variables, there were two groups: one dichotomous and the other cate- gorical, which was mentioned in the methodology section. The dichotomous group consisted of eight variables, namely type of place of residence, sex of household head, currently pregnant, vis- ited by family planning workers in last 12 months, visited health facilities in last 12 months, cur- rently breastfeeding, currently amenorrheic and currently abstaining. As for the categorical variables, these included a mother's age (from 15-19, 20-24, 25-29, 30-34, 35-39, 40-44 and 45 and above), region (eastern, northern, southern and western regions), highest educational level, religion and wealth index (poorest, poorer, middle, richer and richest).

Model 1: Children Having a Cough. Table 6 shows that there are six background variables which are highly significant with children having a cough. A statistically significant association is seen between the regions and children having a cough $(p=0.000)$. The level of significance for this variable was $p<0.005$. Furthermore, the results indicate that children living in the northern regions of Sierra Leone have a 0.7 times greater chance of contracting a cough than those living in the eastern region. The results for an association between the highest educational level of the mother and children having cough are presented in the same table. The data indicate that mothers who had no education were statistically highly significant due to $p<0.001$. Interestingly, for other levels of education, 
there was no significance effect with children having a cough. The third variable used was dichotomous, namely place of residence.

The results in the table indicate that place of residence has a significant effect with children who have a cough. Furthermore, we could conclude that children living in the rural areas are 1.2 times more likely to contract a cough than those children living in the urban areas. This result might be due to there being more health facilities in urban areas. Another interesting influence is mothers currently breastfeeding, which is statistically highly significant to the dependent variable. In addition, we could conclude from the data that children drinking breast milk are 1.3 times less likely to have a chance of contracting a cough than those children who had not been feed breast milk. In terms of the association between currently amenorrhea and children having a cough, the results showed a highly significant effect with an $\exp \beta$ value of 0.81 .

Furthermore, the results indicate that children whose mothers are currently amenorrheic have a 0.8 times greater likelihood of contracting a cough. The results in Table 6 indicated that currently abstaining was highly significant to children having a cough due to $p<$ 0.01. Furthermore, the table shows that children whose mothers had abstained had a 1.2 times greater likelihood of contracting a cough than those whose mothers were not abstaining. In addition, we need to note that religion had shown null values. This could indicate missing values, a possible bias, or even inconsistency in the dataset.

Model 2: Children Having a Problem in the Chest. When looking at the results in Table 6 , we found that the region was considered significant to children contracting problems in the chest due to $p<0.001$. Furthermore, the odds ratio shows that children living in the southern region of Sierra Leone are 1.4 times more likely to have a problem in the chest than those living in the eastern region $(p<0.01)$. The highest educational level of a mother was shown to be significant to mothers who had no education and children having a problem in the chest. As for the other levels of education, there was no relationship shown. According to Table 6, religions had shown to be significant to children having a problem in the chest. However, this was only shown for children who belonged to the Christian faith. As for the other religions (Islam, Baha'i, traditional, none and other), the significance values suggest that there was an error in the data, which could be due to one of the following reasons: missing values, a bias, or an inconsistency in the data.

Type of place of residence indicates that there is significance to children with a problem in the chest $(p<0.005)$. The odds ratio shows that a child who lives in a rural area is 1.7 times more likely to have problems in the chest than a child living in an urban area. Sex of the household showed that there was a relationship with children having a problem in the chest $(p<0.05)$. As for the odds ratio, the results had shown that children who had come from a household whose head was a female are 1.4 times more likely to have a problem in the chest than those children who had come from a household whose head was a male. Furthermore, according to Table 6, mothers 'currently breastfeeding' is statistically highly significant to the dependent variable $(p<0.05)$. In addition, we could conclude from the data that children drinking breast milk are 1.4 times less likely to have a chance of contracting a cough than those children who had not been feed breast milk. 
Table 6. The odds ratio of children having a cough, problems in the chest and diarrhoea by background characteristics in Sierra Leone, 2008.

\begin{tabular}{|c|c|c|c|c|c|c|c|c|c|}
\hline \multirow[t]{2}{*}{ Selected variables } & \multicolumn{3}{|c|}{ Model I. Having cough } & \multicolumn{3}{|c|}{$\begin{array}{l}\text { Model } 2 \text {. Problem in the } \\
\text { chest }\end{array}$} & \multicolumn{3}{|c|}{ Model 3. Diarrhoea } \\
\hline & $\operatorname{Exp}(\beta)$ & \multicolumn{2}{|c|}{$\begin{array}{l}95 \% \text { C.I. for } \\
\text { EXP( } \beta) \text { Lower } \\
\text { Upper }\end{array}$} & \multirow[t]{2}{*}{$\operatorname{Exp}(\beta)$} & \multicolumn{2}{|c|}{$\begin{array}{l}95 \% \text { C.I. } \\
\text { for EXP( } \beta) \\
\text { Lower Upper }\end{array}$} & & \multicolumn{2}{|c|}{$\begin{array}{l}95 \% \text { C.I. for } \\
\text { EXP( } \beta) \text { Lower } \\
\text { Upper }\end{array}$} \\
\hline \multicolumn{9}{|c|}{ Age 5-year groups (Ref: 15-19) } & \\
\hline $15-19$ & 1.00 & & & 1.00 & & & 1.00 & & \\
\hline $20-24$ & 1.26 & 0.74 & 2.2 & 1.05 & 0.51 & 2.18 & 1.79 & 0.38 & 8.58 \\
\hline $25-29$ & 1.35 & 0.82 & 2.23 & 1.24 & 0.64 & 2.39 & 1.82 & 0.42 & 7.88 \\
\hline $30-34$ & 1.25 & 0.76 & 2.04 & 1.05 & 0.55 & 2.01 & 1.72 & 0.41 & 7.28 \\
\hline $35-39$ & 1.45 & 0.88 & 2.39 & 1.29 & 0.67 & 2.49 & 0.81 & 0.18 & 3.71 \\
\hline $40-44$ & 1.09 & 0.66 & 1.82 & 1.01 & 0.52 & 1.98 & 1.02 & 0.22 & 4.63 \\
\hline $45-49$ & 1.07 & 0.61 & 1.88 & 1.12 & 0.53 & 2.33 & 0.87 & 0.16 & 4.81 \\
\hline \multicolumn{10}{|c|}{ Region (Ref: Eastern) } \\
\hline Eastern & 1.00 & & & 1.00 & & & 1.00 & & \\
\hline Northern & 0.74 & 0.58 & 0.95 & 0.81 & 0.55 & 1.19 & 0.50 & 0.25 & 1.02 \\
\hline Southern & 0.84 & 0.65 & 1.08 & 1.42 & 0.97 & 2.06 & 1.06 & 0.54 & 2.08 \\
\hline Western & 0.97 & 0.76 & 1.26 & 1.09 & 0.74 & 1.61 & 0.29 & 0.13 & 0.67 \\
\hline \multicolumn{10}{|c|}{ Highest educational level (Ref: No education) } \\
\hline No education & 1.00 & & & 1.00 & & & 1.00 & & \\
\hline Primary & 0.95 & 0.50 & 1.80 & 1.22 & 0.37 & 4.05 & 0.58 & 0.12 & 2.69 \\
\hline Secondary & 1.45 & 0.76 & 2.76 & 1.74 & 0.52 & 5.85 & 0.68 & 0.14 & 3.28 \\
\hline Higher & 1.18 & 0.62 & 2.23 & 1.86 & 0.56 & 6.17 & 0.54 & 0.12 & 2.58 \\
\hline \multicolumn{10}{|c|}{ Wealth index (Ref: Poorest) } \\
\hline Poorest & 1.00 & & & 1.00 & & & 1.00 & & \\
\hline Poorer & 1.14 & 0.91 & 1.42 & 1.05 & 0.78 & 1.41 & 1.19 & 0.63 & 2.26 \\
\hline Middle & 1.19 & 0.95 & 1.49 & 1.25 & 0.94 & 1.67 & 1.16 & 0.62 & 2.18 \\
\hline Richer & 1.26 & 0.99 & 1.6 & 0.95 & 0.68 & 1.33 & 0.83 & 0.40 & 1.70 \\
\hline Richest & 1.26 & 0.92 & 1.74 & 1.13 & 0.71 & 1.80 & 0.43 & 0.16 & 1.11 \\
\hline \multicolumn{10}{|c|}{ Type of place of residence (Ref: Urban) } \\
\hline Urban & 1.00 & & & 1.00 & & & 1.00 & & \\
\hline Rural & 1.20 & 0.98 & 1.48 & 1.65 & 1.21 & 2.26 & 0.66 & 0.38 & 1.15 \\
\hline \multicolumn{10}{|c|}{ Sex of household head (Ref:Male) } \\
\hline Male & 1.00 & & & 1.00 & & & 1.00 & & \\
\hline Female & 1.03 & 0.86 & 1.23 & 1.35 & 1.06 & I.7I & 1.20 & 0.74 & 1.96 \\
\hline \multicolumn{10}{|c|}{ Currently pregnant (Ref: No or unsure) } \\
\hline No & 1.00 & & & 1.00 & & & 1.00 & & \\
\hline Yes & 1.07 & 0.80 & 1.44 & 1.00 & 0.65 & 1.54 & 0.94 & $0.4 I$ & 2.16 \\
\hline \multicolumn{10}{|c|}{ Visited by a FP worker in last 12 months (Ref: No) } \\
\hline No & 1.00 & & & 1.00 & & & 1.00 & & \\
\hline Yes & 0.94 & 0.74 & 1.18 & 1.09 & 0.80 & 1.50 & 0.83 & 0.40 & 1.75 \\
\hline \multicolumn{10}{|c|}{ Visited health FC in last 12 months (Ref: No) } \\
\hline No & 1.00 & & & 1.00 & & & 1.00 & & \\
\hline Yes & 1.12 & 0.97 & 1.29 & $\mathrm{I} .14$ & 0.93 & 1.39 & 0.95 & 0.63 & 1.43 \\
\hline
\end{tabular}


Table 6. (Continued)

\begin{tabular}{|c|c|c|c|c|c|c|c|c|c|}
\hline \multirow[t]{2}{*}{ Selected variables } & \multicolumn{3}{|c|}{ Model I. Having cough } & \multicolumn{3}{|c|}{$\begin{array}{l}\text { Model } 2 \text {. Problem in the } \\
\text { chest }\end{array}$} & \multicolumn{3}{|c|}{ Model 3. Diarrhoea } \\
\hline & $\operatorname{Exp}(\beta)$ & \multicolumn{2}{|c|}{$\begin{array}{l}95 \% \text { C.I. for } \\
\text { EXP( } \beta) \text { Lower } \\
\text { Upper }\end{array}$} & \multirow[t]{2}{*}{$\operatorname{Exp}(\beta)$} & \multicolumn{2}{|c|}{$\begin{array}{l}95 \% \text { C.I. } \\
\text { for EXP( } \beta \text { ) } \\
\text { Lower Upper }\end{array}$} & & \multicolumn{2}{|c|}{$\begin{array}{l}95 \% \text { C.I. for } \\
\text { EXP( } \beta) \text { Lower } \\
\text { Upper }\end{array}$} \\
\hline \multicolumn{9}{|c|}{ Currently breastfeeding (Ref: No) } & \\
\hline No & 1.00 & & & 1.00 & & & 1.00 & & \\
\hline Yes & 1.33 & 1.07 & 1.66 & 1.22 & 0.54 & 1.21 & 1.16 & 0.63 & 2.15 \\
\hline \multicolumn{10}{|c|}{ Currently amenorrhea (Ref: No) } \\
\hline No & 1.00 & & & 1.00 & & & 1.00 & & \\
\hline Yes & 0.81 & 0.68 & 0.96 & 1.40 & 1.03 & 1.90 & 0.66 & 0.40 & 1.10 \\
\hline \multicolumn{10}{|c|}{ Currently abstaining (Ref: No) } \\
\hline No & 1.00 & & & 1.00 & & & 1.00 & & \\
\hline Yes & 1.22 & 0.98 & 1.52 & 1.18 & 0.87 & 1.61 & 1.10 & 0.59 & 2.07 \\
\hline
\end{tabular}

Model 3: Children Having Diarrhoea. Table 6 indicates that only one variable had shown a relationship with children having diarrhoea. The region of the child had shown to have a significance of $p<0.001$. First, the table shows that the eastern region of Sierra Leone has a higher significance for children to contract diarrhoea than any of the other regions. Second, it shows that the western region had the second highest significance level, with the northern region $(p<0.01)$ being the third. As for the southern region, this was shown not to be significant. Furthermore, the odds ratios indicate that children living in the western region are 0.3 times more likely to contract diarrhoea than those living in the eastern region. As for those in the northern region, the results showed that there is a 0.5 times greater likelihood of a child contracting diarrhoea from this region than from the eastern region. In summary, the regional variation was found only for the children having a cough, but there were no effects with diarrhoea and problems in the chest.

\section{Discussion}

The first aspect we looked at was factors associated with child mortality. From our results, we had concluded that there are four factors that are statistically significant to child mortality. The first was place of residence. In 1988, Bailey had found that the place of residence was a contributing factor towards child mortality in Sierra Leone. As per the study analysis we have kept all the variables in the concern tables due to clarity of purpose and only significant variables were discussed. In our results, we also found this to be true. It was interesting to find that a higher percentage of children had died in the urban areas compared to those in the rural areas, even though the rural areas are the places where most of the economic wealth comes from. As for possible reasons for the higher percentage of children dying in urban areas, we concluded that: first, there could have been possible migration and the place of residence at the time of death was not the real onset of death. Second, the medical centres in the urban areas could have not been well equipped or had no medication available. As for the rural areas, the distance to a medical facility or lack of medication at the facility might have been the problem.

The second factor was birth number. From our review of the literature, we found that birth number is significant to child morality, as we have also concluded in our study. However, 
Van Ginneken and Kembo (2009) stated that a U-shaped relationship was found between a child's birth number and death, but in our study this is not the case. In our results, we found that, even though fewer children had a birth number higher than 10, this showed the highest percentage of deaths. Those children with a birth number between one and three had the smallest percentage of deaths. Furthermore, we found that as the birth number of a child increases, so does the percentage of deaths. The possible reason for this is that a mother who has her first child tends to be more overprotective and wellcared-for than for children born after that. Furthermore, it could be found that caregivers to children with a higher birth number were either inexperienced, the child's older siblings, or both.

The third significant factor associated with child morality was religion. In our results we found that the country is predominantly Muslim, while the second highest religion was Christianity. As for other religions, which included Baha'i, traditional, none and other, there were a very small percentage of these. Furthermore, in our results, we found it surprising that other religions had the highest percentage of deaths, while Muslims (who were the majority) had the smallest percentage of deaths. The potential motivation for this is that some people use their religion as a decision- making tool as stated by certain researchers (Agadjanian and Menjivar, 2008; Ellis and Haar, 1998). These types of decisions include whether a child could be taken to a medical facility or receive any treatment when sick.

In addition, our study found that the type of toilet facility used by a child is statistically significant to child mortality. From our results, we found it interesting that, even though there were a small number of children using a flushing toilet, the percentage of children that died compared to those who had no facility was much higher. The possible explanation for the type of toilet facility being used by a child as a factor in child mortality is that the infrastructure in Sierra Leone is not of a high standard. In addition, when we looked at the highest percentage of child deaths, it was found that they were from children using the river/stream as a toilet facility. The rivers/streams are breeding grounds for potential viruses and bacteria. This was shown in a study by Clasen and Bastable (2003) when they explained how people's water sources were being contaminated by faeces. Also, there could have been leakages from the sewage systems that people were unaware of that caused those children who died to contract a vulnerable disease.

Further, in the study, we looked at four vulnerable diseases associated with children dying, which were ARI, pneumonia, diarrhoea and measles. However, since no data was available on cause of death, we looked at the effects of these diseases on children in Sierra Leone. From our results, we can conclude that, for ARI, there was only one factor statistically significant for children who showed signs of ARI, which was the roof material of the household. In our study, there were a number of cases that had not answered this question. However, from those who did answer, it was made clear that the highest percentage of child deaths were from households using rudimentary material. The rudimentary material used was wood and palms/bamboo, which people used in their households. These materials may not have been treated correctly and the child might have inhaled something from them while in the household, causing the child to become 
sick. Sierra Leone is a country that has vast forests and this could be a reason why rudimentary material was used. Madhi and Klugman (2006) had stated five factors that could help reduce the number of children being infected with ARI. However, in our study we found none of these factors to be significant.

As for pneumonia, there were no factors associated with children showing signs of the dis- ease. This is surprising since Onoja (2010) had stated that at least 1.6 million children had died due to pneumonia, of which $98 \%$ had come from developing countries. Diarrhoea was the third disease we looked at. In our results, we found that one known factor was associated with children contracting the disease, which was the source of the household's water. The potential reason for this is that some areas of Sierra Leone's people use the rivers/streams as their toilet facility, which contaminates the water and, without proper purification of it, we would find a lot of children getting sick, as stated by Clasen and Bastable (2003). This was reiterated by Gunther and Fink (2011), who stated that, if proper investment in water purification is made, child mortality could be reduced. Furthermore, we have established in the rationale that Sierra Leone has emerged from a civil war and is trying to build its infrastructure. This means that water purification and sanitation plants are being upgraded or built and therefore water contamination is still happening in the country.

The last disease we looked at was measles. This disease also had one factor statistically significant to children contracting the disease. This factor was the place of residence. Measles is a disease that has been under control for years as vaccinations are available. However, in developing countries, this is not always the case, as stated by World Vision International (2010). In our study we found that more children had shown signs of measles in the urban areas rather than in the rural areas. The potential cause of the measles is people coming into the country and passing it on to other people. Another is that the virus was always there, but in rural villages and as

Furthermore, we have found that children who had contracted a cough and those with a problem in the chest had six and five variables significant to each respectively. What makes this interesting is that these two symptoms are signs for the diseases pneumonia and ARI. In addition, we found it interesting that both these two variables had three factors in common, which were region, place of residence and currently breastfeeding. From the region, it was shown that children were 0.7 times more likely to contract a cough in the northern region, while children living in the southern region had a 1.4 times greater likelihood of having problems in the chest. As for place of residence, it was found that 1.2 times more children would contract a cough and 1.7 times more children would have a problem in the chest from staying in the rural areas. In the case of mothers currently breastfeeding, it was found that 1.3 times more children would contract a cough, while 1.4 times would have problems in the chest.

As for children who still had diarrhoea, it was shown that only one variable was significant. This was the variable 'region'. There were two regions that had shown that children who still had diarrhoea were significant; that is, the southern and northern regions of Sierra Leone. 
This study has shown a path for the Sierra Leone government to help it reduce the high child mortality rate. In order for the government to help reduce child mortality, there are a few key issues that need to be implemented. First, the government would need to distribute basic needs to its people, especially in the rural area. Access to clean drinking water, proper toilet facilities and access to medical treatment should be the highest concern for the government. Second, there should be at least two types of campaigns run to promote, first, basic amenities sanitation and proper healthcare and, second, immunization to reduce the occurrence of children contracting vulnerable diseases. Furthermore, there is genocide of girls occurring throughout the world. An informative workshop should be run throughout the rural and urban areas of Sierra Leone to stress the importance of girls in society and how a girl is an asset to any area, city, or country in the world. Finally, the study showed how maternal and environmental factors have significance on whether a child would contract a vulnerable disease. Therefore the government should start to rebuild its infrastructure, as well as implement or improve programmes currently running to aid in decreasing the amount of children contracting diseases. This will allow child mortality levels to decrease in Sierra Leone.

\section{Conclusion}

In Sierra Leone there have not been many studies carried out on epidemiology effecting child mortality. However, if we look at the selected disease patterns mentioned in this article, it shows that diarrhoea is the disease that affects most children, while pneumonia and ARI are second and third respectively. However, as for measles, a disease that in the 21st century is rarely contracted, the study shows there are a fair number of children contracting this disease, making it clearer that some children are not being vaccinated. Due to this, we would recommend that the country keep promoting child vaccination, reiterating how important it is. This will aid in reducing the number of children contracting measles. Also, we would like the country to run a campaign on hygiene in the household, as well as grant the most basic of needs to the rural areas, which is the provision of proper toilets and purified piped water. This will aid in reducing the number of children being infected by diarrhoea. Furthermore, free testing of ARI and pneumonia should be available for adults. This will allow children who contracted this airborne disease to be treated or, if not, prevent the child from contracting it. The concerned government should try to implement universal education systems to prevent the spread of vulnerable diseases. Healthcare providers should give proper propaganda for pulse polio vaccination, promote community participation, whilst more attention to these issues should be given by the mass media, newspapers and so forth. This will be of immense worth in this juncture. Therefore further research is urgently needed in this country.

\section{Acknowledgements}

The authors would like to thank the financial assistance of the National Research Foundation (NRF) towards this research which is hereby acknowledged. Opinions expressed and conclusions arrived at are those of the authors and are not necessarily to be attributed to the NRF. 


\section{References}

Agadjanian V and Menjivar C (2008) Talking about the 'epidemic of the millennium': Religion, informal communication and HIV/AIDS in Sub-Saharan Africa. Social Problems 55: 301-321.

Bailey M (1988) Factors affecting child mortality in Sierra Leone. Journal of Tropical Pediatrics 34: 165-168.

Behm H (1983) Final Report on Research Projection Infant and Child Mortality in Third World Countries. Document presented at the Inter-centre Cooperative Research Programme, World Health Organisation. Available at: http://www.cicred.org/Eng/Publications (accessed 6 September 2012).

Clasen TF and Bastable A (2003) Faecal contamination of drinking water during collection and household storage: the need to extend protection to point of use. Journal of Water and Health 1(3): 109-115.

Gordon B, Mackay R and Rehfuess E (2004) Inheriting the World: The Atlas of Children's Health and the Environment. Geneva: World Health Organization.

Gunther I and Fink G (2011) Water and Sanitation to Reduce Child Mortality: The Impact and Cost of Water and Sanitation Infrastructure. Washington, DC: The World Bank.

Institute for Health Metrics and Evaluation (2010) Infant and Child Mortality Estimates by Country 1970-2010. Seattle: Institute for Health Metrics and Evaluation.

International Centre for Transitional Justice (2010) Sierra Leone: Submission to the Universal Periodic review of the UN Human Rights Council. Available at: http://ictj.org/sites/ (accessed 6 September 2012). Lopez AD, Ahmad OB, Guillot M, Ferguson BD, Salomon JA, Murray CJL, et al. (2002) World Mortality in 20oo: Life Tables for 191 Countries. Available at: http://www.who.int/healthinfo (accessed 6 September 2012).

Madhi SA and Klugman KP (2006) Acute respiratory disease. In: Jamison DT, Feachem RG, Makgoba MW, Bos ER, Baingana FK, Hofman KJ, et al. (eds) Disease and Mortality in Sub-Saharan Africa, 2nd edition. Washington, DC: World Bank, 149162

Measure DHS (2008) Survey Dataset [Sierra Leone Demographic and Household Survey]. Available at: http://www.measuredhs.com (accessed 6 September 2012).

Morley D (2010) Saving Children Under Five and their Mothers: The Only Innovation

Needed - Dedication. Paper presented at the Accountability, Innovation and Coherence, Toronto. Available at: http://www. g8.utoronto.ca/conferences/2010 (accessed 6 September 2012).

Nannan N and Hall K (2010) HIV and Health - Child Mortality (IMR \& U5MR). Available at: http://www. childrencount.ci.org.za/indicator (accessed 6 September 2012).

Oloo JA (2005) Child mortality in developing countries: Challenges and policy options. Eastern Africa Social Science Research Review 21(2): 1-17.

Onoja C (2010) Nigeria: Nigeria has the highest child mortality rate in Africa. NGO News Africa. Available at: http://http://www.ngonewsafrica.org (accessed 6 September 2012).

Skolnik RL (2008) Essentials of Global Health. Sudbury, MA: Jones And Bartlett Publishers. 
Steadland S and Skoglund K (2008) Reduce Child Mortality UN Millennium Development Goal 4. Available at: http://www.coursehero.com/ (accessed 6 September 2012).

Turay E (2010) A Special World Pneumonia Day report: Sierra Leone's fight to improve Healthcare. Avail- able at: http://www.one.org/international (accessed 6 September 2012).

Uddin J, Hossain Z and Ullah MO (2009) Child Mortality in developing countries: A statistical analysis. Journal of Applied Quantitative Methods 4(3): 270-283.

United Nations (2010) Goal 4: Reduce Child Mortality. (Fact sheet). Available at: http://www.un.org/millen-niumgoals (accessed 6 September 2012).

United Nations, Department of Economic and Social Affairs, Population Division (2011) Detailed Indicators (Indicators for Under-Five Mortality). Available at: http://esa.un.org/wpp (accessed 6 September 2012).

Van Ginneken JK and Kembo J (2009) Determinants of infant and child mortality in Zimbabwe: Results of multivariate hazard analysis. Demographic Research 21: 367384 .

World Health Organization (2010) Communicable Disease. http://www.searo.who.int/en/ (accessed 6 Sep- tember 2012).

World Vision International (2010) Global Health and Nutrition: Infectious Disease. Available at: http://www. wvi.org (accessed 6 September 2012). 


\section{Author biographies}

Saarah F Davids successfully completed an MPhil at the Department of Statistics and Population Studies, University of the Western Cape, South Africa.

A Sathiya Susuman has an MA, MPhil in Population Studies and a PhD in Demography. He has specialized in the social science research area of demographic analysis and reproductive health for 12 years. His specific research area is fertility, mortality and public health. He has published several articles in reputed journals. He currently works as Senior Lecturer in Demography at the Department of Statistics and Population Studies, University of the Western Cape, South Africa.

Latief Abduraghiem has an MSc in Statistics and is a Lecturer at the Department of Statistics and Population Studies, University of the Western Cape, South Africa. 